\section{Charles Janeway, Jr.}

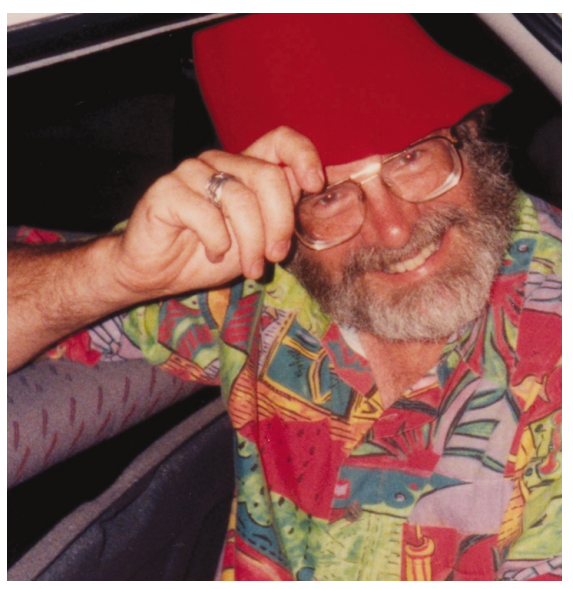

Charlie Janeway passed away on April 12, 2003 and with him went a good chunk of immunological creativity. Because several tributes relating to his official accomplishments have already been written, I will focus on the man and scientist as I knew him.

Charlie and I met in 1977 in Cambridge, when I was a graduate student visiting a friend and he was a young assistant professor at Yale. Having just read a paper of his in the April edition of Nature, and having decided (with the arrogance of a third-year grad student) that it was wrong, I asked him if it had been an April fool's joke. Without batting an eye, and ignoring my rudeness, Charlie asked me why I thought that. The three of us then spent the next few hours in a pub discussing that paper (which turned out to be right, of course) and many other aspects of immunology, Charlie treating me throughout as an equal despite the differences in our immunological knowledge. This was one of his great features. He loved students and treated us, if we were capable, as colleagues without ever hinting that we should hold our tongues and not argue with the "adults".

As well as being a great teacher, Charlie was a pioneer in several immunological fields, tackling problems that mattered, rather than those that were simply fashionable. For example, his group was the first to ask whether less antigen might be needed for thymic tolerance than for peripheral activation; i.e., does the immune system have a built-in safety margin for self-tolerance? He and his postdoc, Alexander Rudensky, were the first to biochemically characterize peptides from MHC class II. $\mathrm{He}$ and Mark Mamula were the first to show that B cells were involved in "epitope spreading," a phenomonon that has since been studied by several groups working in autoimmunity. As importantly, Charlie had an amazing intuition and an ear for apparently bizarre phenomena on the margins of immunology, coupled with the ability to bring them to center stage. Long before superantigens, for example, became a popular subject, Charlie studied them and suggested that a superantigen acted as a "hook" to glue $\mathrm{T}$ cell receptors to MHC molecules, a suggestion that other labs later showed to be true.

But of course, Charlie will most be remembered for his championing of the innate immune system as the controller of immunity. At a time when most labs were interested only in antigen recognition, believing that this controlled immune responses, Charlie looked around and asked a very basic question. "Why," he asked, "was the mere foreignness of a protein not enough to elicit immunity? Why did we need to add adjuvant (noxious substances like mineral oil, mycobacteria, or aluminum hydroxide) in order to get a decent response to a vaccine?" The self-nonself model neither predicted nor explained the need for adjuvant. Charlie gnawed at this problem (which he called the "immunologists' dirty little secret") for years, slowly coming to an important understanding that caused a major switch in immunological thinking. He decided that immune responses could not occur unless antigen-presenting cells were first activated, and that they were activated via pattern recognition receptors (PRRs) that recognized evolutionarily conserved molecules on infectious nonself organisms. In effect, he said that the immune system's default state is off and that it can be turned on by bacteria.

Then, in the coup that caused the immunological community to finally take notice, Charlie and Ruslan Medzitoff found the PRRs. They studied Drosophila, arguing that the PRRs ought to be evolutionarily ancient. Using the fruit fly's innate immune sensor, Toll, they found the mammalian Toll-like receptors (TLRs), which are now studied by labs around the world. Charlie's PRRs had come of age.

When I asked him (in my now older and "wiser" mode as his ever-challenging colleague) how his model explained autoimmunity or immune responses to tumors or transplants (which are not usually covered in bacteria), Charlie answered that I needn't worry because we hadn't evolved to deal with these things. Transplants, after all, were a modern invention, and tumors and autoimmunity killed us late in life, after procreation, and thus were not subject to evolutionary pressure.

As usual, I disagree with Charlie. A model of immunity must explain transplants, tumors, and autoimmunity in order to be complete. And I wonder sometimes if the TLRs really evolved to see bacteria or if the bacteria evolved to see the TLRs. However, the disagreement, and the discussions we had, honed both of our thoughts. There are few scientists like Charlie, with enough self-confidence to argue heatedly with a colleague who has put out an opposing model ... and then go dancing with her. Charlie and I danced a lot, argued a lot, and had a wonderful time doing it. I will remember him as one of the most exciting, decent, and thoughtful immunologists on the planet.

\section{Polly Matzinger}

Ghost Lab, LCMI, NIAID, NIH pmatzinger@niaid.nih.gov 